\title{
sciendo
}

\section{Is there a Link between Sustainability, Perception and Buying Decision at the Point of Sale?}

Julia Lamberz, Thorsten Litfin, Özlem Teckert, Gunther Meeh-Bunse

Osnabrück University of Applied Sciences, Faculty of Management, Culture and Technology, Germany

\section{Abstract}

Background: If retailers and brand manufacturers of food succeed in presenting their products at the point of sale, quickly generating a high level of attention, the likelihood of a purchase is significantly increased. Particularly, in recent years, they have been relying on the megatrend of sustainability. The importance of sustainable food has grown accordingly. Hence, an increasing number of manufacturers are challenged to communicate the sustainability of their products via packaging and displays at the point of sale. Objectives: The aim of this article is: to examine to what extent the design of individual packaging and display elements of new sustainable direct juice succeeds in visually communicating sustainability aspects. At the same time the willingness to pay of customers interested in sustainability must be commercialized. Methods/Approach: The focus is on a real shopping situation in conditions that are as regular as possible. The perception of a display must be recorded by eye-tracking technology. A preliminary survey must examine consumers' attitudes towards sustainable food in order to relate it to the perception of individual display elements. For this purpose, the eye-tracking technology was combined with a survey of 32 customers. Results: The results demonstrate that customers with a positive attitude towards sustainable food behave in the following way: they fix individual packaging and display elements that refer to sustainable components for a longer period of time; they remember product features better and they tend to have a slightly higher willingness to pay for the sustainable direct juice. Conclusions: The configuration of an authentic and natural shopping situation provides the manufacturer with concrete recommendations for the design of the display. This communicates the sustainability of its product and thus generates the desired attention.

Keywords: consumer behaviour, eye-tracking, sustainability, visual merchandising, visual attention

JEL classification: M31, M37

Paper type: Research article

Received: Dec 17, 2019

Accepted: Apr 19, 2020

Citation: Lamberz, J., Litfin, T., Teckert, Ö., Meeh-Bunse, G. (2020), "Is There a Link between Sustainability, Perception and Buying Decision at the Point of Sale?", Business Systems Research, Vol. 11, No. 3, pp. 1-13.

DOI: https://doi.org/10.2478/bsrj-2020-0023 


\section{Introduction}

If retailers and brand manufacturers of foods succeed in presenting their products at the point of sale in such a way that they quickly generate a high level of attention, their purchase probability increases significantly. This is because most products and brands from the fast moving consumer goods sector spontaneously end up in the shopping cart at the point of sale. According to a number of studies, the share of socalled instore decisions must be around 65 percent. For half of these purchases, the consumer only knows which category of goods he wants to buy a product from (Häusel, 2016). The visual stimuli are of outstanding importance here, since 85 percent of the products seen first are purchased without further consideration of alternatives. Even 90 percent of purchasing decisions are made by only taking a quick look at the front of a product. Consequently, consumers make decisions visually buying the products they see (Nordfält, 2011). While shopping, consumers are influenced by a variety of factors. In addition to the wide range of products on offer, purchasing decisions are also influenced by the presentation of goods on displays, salesroom design and advertising banners. These stimuli are known as bottom-up factors. Like top-down factors - such as attitudes towards a particular product - they help to draw attention to particular products. As a result, retailers and brand manufacturers strive for presenting products and brands in a way that consumers see them first. In particular, displays play a key role in the presentation of fast moving consumer goods. These are also referred to as impulse goods at the point of sale (Behe et al., 2013; Diederichs \& Göbl, 2018).

Sustainability is one of the megatrends gradually establishing themselves in our society. Accordingly, the importance of sustainable consumption is constantly growing. Food manufacturers and retailers are adapting this development in order to attract attention and convince customers of their products. In recent years, consumers have therefore increasingly found sustainable foods on the shelves of retail traders. The importance of sustainable foods grew accordingly and so did the turnover, which rose by 15 percent in 2017 to reach billions (Fairtrade Deutschland, 2017). Manufacturers of sustainable foods are faced with the task of communicating the term "sustainability" via packaging and display elements. However, from the customer's point of view there is no clear definition of the term "sustainable foods". This is because, consumers associate the term with many properties such as production without artificial additives or ecological and regional production (Aiking \& de Boer, 2004; Grunert, 2011; von Meyer-Höfer, 2016). Von Meyer-Höfer surveyed 570 consumers in Germany and Switzerland on the properties of sustainable foods. According to the survey, consumers expect sustainable foods to have ecological, regional, ethical and social properties. Since these properties have only a limited impact on taste and appearance, they cannot be clearly linked to food. It is therefore difficult for consumers to recognise sustainable product properties at the point of sale (von Meyer-Höfer, 2016). Producers and traders of sustainable foods must communicate the sustainability of their products via packaging and displays at the point of sale to notice the trend towards sustainability and use it for their own benefit.

The objective of this article is to demonstrate how the design of displays can influence the visual perception of sustainable foods at the point of sale. To this end visual perception and shopping behaviour at the point of sale as well as the potential of applying eye-tracking approaches will be examined from a theoretical point of view. Building on this, the extent to which the design of individual display elements succeeds in visually communicating sustainability will then be examined for a new sustainable organic juice. The significance of sustainability for customers will also be determined. Furthermore, extent to what this significance is related to the perception 
of individual display elements are in the research focus (Lamberz et al., 2019). It is also considered to what extent the importance of sustainability influences the willingness to pay for one litre of sustainable direct juice. For this purpose, the use of eye-tracking technology will be combined with a questionnaire.

The paper consists of five parts. After (1) the introduction, (2) a literature review of visual perception and purchasing behaviour at the point of sale and its measuring by eye tracking technology are described as a basis for the derived research propositions. Thereafter, (3) the research methodology is presented, including sample description and research instruments. (4) Data analysis and main research findings are provided in the fourth part. Finally, (5) research results are discussed from both the theoretical and the managerial standpoint. In addition, directions for future research are outlined.

\section{Literature review}

\section{Visual perception and purchasing behaviour at the point of sale}

To assess how products and brands influence the purchase decision at the point of sale, the analysis of customer perception is important (Pieters \& Warlop, 1999). Products are viewed with the eye of a customer and the brain processes the perceived images. This visual cognitive processing consists of a series of stops (fixations) and jumps (saccades) (Russo, 1978). Simultaneously, the product fixation processes the information top-down and bottom-up. Consumers are not only influenced by externally perceived stimuli such as the colour design of product packaging and displays (bottom-up factors) but by internal stimuli such as individual goals, product settings and memories (top-down factors). Some stimuli are expected and foreseen and the inner stimuli affects the perception and evaluation of external stimuli (Wedel \& Pieters, 2008).

The design of these external stimuli is of particular importance since about 65 percent of decisions are made spontaneously during the shopping process. The consumer only decides for half of his or her purchases based upon previous knowledge about a particular category or brand (Häusel, 2016). In addition, consumers have a decreasing amount of time to shop. Therefore, the viewing times of product packaging are in a range of a few seconds (Huddleston et al., 2015; Pieters et al., 1999,). During this time, 90 percent of all purchasing decisions are made by taking a quick look at the front of the product packaging (Grunert, 2011). Pieters et al. (2002) found in an eye-tracking study that especially the information in the areas fixed by the eyes is remembered. In contrast, the information that is only perceived peripherally remains less memorable.

Therefore, consumers make decisions with their eyes and buy the products they see (Nordfält, 2011). At the same time, consumers can be influenced by many factors while shopping. In addition to the wide range of products on offer, the purchasing decision is influenced by the design of the sales room, the presentation of the goods on displays and the product packaging (Gröppel-Klein, 2007). In an eye-tracking study at the point of sale, Clement et al. (2013) identified the elements on packaging influencing the purchase decision. Based upon these insights they proposed a packaging design with simple features in order to achieve an increased probability of initial attention. Ultimately, this attention also has a positive influence on the purchase decision. For producers this means not only placing the goods in such a way that they are perceived and found by the consumer but also that packaging and displays are designed to be simple and target-group-oriented as an important point of contact to the customer (Huddleston et al., 2015). 


\section{Eye-tracking studies}

Whether and for how long individual elements of displays and packaging are perceived can be measured by using eye-tracking methods (Duchowski, 2007). While many eye-tracking studies were carried out at the laboratory to examine product packaging (Huddleston et al., 2018), there are only a few studies that were realised in a regular shopping environment. Eye-tracking studies at the point of sale demonstrated that individual display and packaging elements have an influence on visual attention, search and buying intention as well as willingness to pay (Clement et al., 2013; Grunert, 2011; Huddleston et al., 2015; Janssen \& Hamm, 2012). Laboratory studies analysing the perception of packaging demonstrated that the logo and images attracted attention, while the product name had little impact (CholoewaWójcik \& Kawecka, 2015; Wästlund et al., 2018). Van Loo et al. examined the perception of individual labels that visualize sustainability (e.g. Fair Trade and Rainforrest Alliance) in an eye-tracking laboratory study. They also established connections between consumers' attitudes to individual sustainability attributes and the visual perception of sustainability labels. The results confirm that the importance of sustainability attributes for visual attention is relevant. Consumers who are more concerned with and focused on sustainability attributes value them more (Van Loo ef al., 2015).

Consumers who associate individual packaging elements (labels) with sustainability have a higher probability of buying this product, and they also place more trust in it (Samant et al., 2016). To measure the perception of individual labels, logos and images, the authors correlated the eye-tracking metrics "total fixation duration" and "total fixation count" (Samant et al., 2016, Huddleston et al., 2015, van Loo et al., 2015, Clement et al., 2013). In addition to bottom-up factors (sustainability labels, label information), van Loo et al. (2015) and Samant and Seo (2015) also incorporated topdown factors (label knowledge, attitude towards sustainability attributes). These factors are considered to influence perception according to the theory of Wedel and Pieters (2008).

\section{Hypothesis resulting from the literature review}

In reference to the perception of elements on packaging that visualize and communicate sustainability, an eye-tracking study revealed that 63 percent of consumers looked at the front of the packaging before buying the product and neglected other areas at the same time (Grunert, 2011). The understanding of elements such as sustainability labels often depends on the design of the label. The label must be self-explanatory in order to associate it with "sustainability" at a glance. Grunert et al. (2014) discovered that consumers who value collectivist values more than individual values pay more attention to sustainability issues related to food (Grunert et al., 2014). Van Loo et al. (2015) examined visual attention employing an eye-tracking experiment. They were able to confirm that consumers with a higher sustainability awareness spend more time looking at sustainability labels (e.g. the Fairtrade label) (Van Loo et al., 2015). Based upon this, we formulate the first hypothesis:

$\mathrm{H1}$ : Consumers with a positive attitude towards sustainable and regional foods look longer at individual display elements that address sustainability aspects.

In addition, it should be examined to what extent consumers regard this direct juice as a sustainable foodstuff and, after shopping, remember the display elements that should visualise the sustainability dimensions. Lee and Ahn (2012) showed in a study that only the total fixation duration and not the number of short fixations counts influences the memory of different elements on advertisements. The longer the 
respondents looked at an element of an advertisement, the better they could remember it (Lee \& Ahn, 2012). Based on these results, the metric "total fixation duration" is used for the present study in relation to the memory measured in the questionnaires. It was of particular interest to measure differences in behaviour with regard to the memory of individual display elements between customers with a positive or less open-minded attitude towards sustainable foods. On this basis, we establish the second hypothesis:

$\mathrm{H} 2$ : Consumers with a positive attitude towards sustainable and regional foods remember more strongly individual display elements that visualise sustainability aspects.

Previous studies on the willingness to pay of consumers with a high level of environmental awareness and a positive attitude towards buying sustainable foods demonstrated that purchasing behaviour can be influenced (Grunert, 2011; Grunert et al., 2014). Janssen and Hamm (2012) carried out choice experiments and structured interviews with over 2,400 consumers of organic food in six European countries. They discovered that consumers who prefer organic food have a higher willingness to pay than occasional shoppers (Janssen \& Hamm, 2012) do. However, another study found that the main obstacle for not buying sustainable foods was the price perceived as too high (Grunert, 2011). Based on these studies, we put forward the third hypothesis:

H3: Consumers with a positive attitude towards sustainable foods have a higher willingness to pay.

\section{Methodology}

\section{Research instrument}

To test these three hypotheses, eye-tracking technology was combined with a survey. The research instrument consisted of two parts. First, the field study examines the perception of bottom-up factors (individual display elements) of consumers. EyeTracking technology is applied to measure the perception. Second, consumers are asked about their attitudes towards sustainable food with the help of a preliminary survey. Subsequently, the analysis is designed in a way to relate these top-down factors with the perception of individual display elements. Previous eye-tracking studies demonstrated that bottom-up factors influence visual attention in brand searches significantly more than top-down factors (Chandon et al., 2009; Wedel \& Pieters, 2008). Displays play a special role because they have a positive influence on purchasing decisions. Hence, consumers who spend a lot of time looking at displays are more likely to buy the product (Behe et al., 2013).

For this purpose, 32 consumers were recruited before shopping in a supermarket in the town of Nordhorn (Lower Saxony, Germany). All participants were rewarded with a $5 €$ gift voucher from the supermarket. At first, the test persons were informed about the course of the study, and they were asked to provide information on sociodemographic characteristics (age and gender) as well as their assessment of sustainability aspects (figure 1, step 1: preliminary interview). Based on the results of von Meyer-Höfer (2016), the importance of the sustainability aspects "regionality", "ecological production", "socially committed company" and sustainable product was asked on a five-step Likert scale (from "agree" to "disagree"). In the second place, the test persons were given the task of buying the organic juice "Emsländer", whereby the purchasing area was limited to the vegetable department of the supermarket. The test subjects' eye movements were recorded during the shopping process with the help of "Tobii Pro Glasses 2" eye-tracking glasses (figure 1, step 2: verification of the perception). The individual design elements of the display were defined as areas of 
interest (AOI) to communicate the sustainability of the organic juice. The visual attention was captured with the eye-tracking metric "total fixation duration" of this AOls. In the third place, the test persons were asked to answer questions about their memory of pictures, slogans and place of production on the display and the juice bottle on a five-step Likert scale ("I fully agree" to "I do not agree at all") (see table 2). In step 3 it was asked whether consumers with a positive attitude towards sustainability have a higher willingness to pay. Another question focussed on the willingness to pay for one litre of direct fruit juice from the region and form organic production (Figure 1, step 3: subsequent interview). The task was to detect: (1) whether consumers with a positive attitude towards sustainable foods gave the display elements at the point of sale greater visual attention and (2) consumers remember the design elements of the display better. For this reason the "total fixation duration" of AOls was related to the survey results by means of mean value comparisons (figure 1, step 4: evaluation, visualisation and consolidation of the results).

Figure 1

Alignment of the eye-tracking study

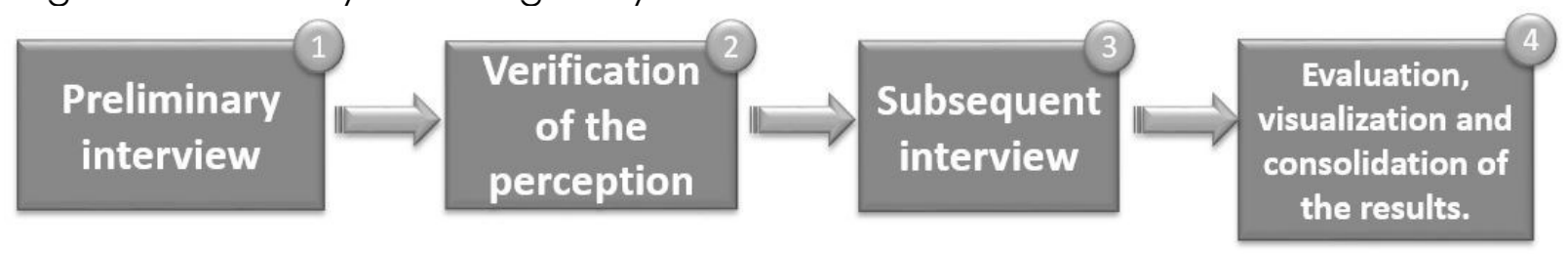

Source: author's illustration

\section{Data and statistical methods}

The eye-tracking data collected in the filed study were analysed in the following steps. The display was divided into a total of 6 AOls visualizing the sustainability aspects displayed in figure 2. A total of 25 out of 32 participants noticed the display. The analysis of the heat map in Figure 2, which displays the intensity with which the test persons looked at the individual AOls, confirms a total of four focal points of the glances: (1) the image "three bottles", (2) the headline 1 with the brand name "Emsländer", (3) the advertising slogan "local berries" and (4) the picture 1 with "Apples, currants and bilberries".

In order to verify whether consumers with a positive attitude towards sustainable foods looked longer at individual display elements, the questions on the importance of the components "regionality", "ecological production", "sustainable product" and "social company" were first combined into a construct "sustainability as a whole". The corresponding Cronbach alpha value of .802 indicates a high internal consistency of this construct. Based on the overall sustainability construct, the test persons were divided into two groups: "sustainability important" and "sustainability unimportant". The group separation was carried out on a scale of 5 (agree (1.00) to disagree (5.00) at a value of 2.00. The mean values of the two groups of respondents "Sustainability important" $(n=15)$ and "Sustainability unimportant" $(n=17)$ were then compared in relationship to the individual AOls. Furthermore, the mean values from the surveys on individual packaging or display elements were compared. The t-test was carried out to control the significance of the differences in mean values. 


\section{Results}

The results of the filed study showed no substantial and significant differences in gender. The distribution between men and women was largely balanced. Due to the low sample size, the eye-tracking metrics only show a tendency towards a stronger consumers' perception of individual images, slogans and headlines with a positive attitude towards sustainable foods. Heading 2 with the slogan "Superfood Blend of Berry Juice", which is intended to express both the special character of the drink and a possible area of use as a mixed drink, is considered less intensively. The same applies to picture 2 with the fruits "elderberry, currant, blueberry". Overall, the lower part of the display, which is no longer at eye level of the test persons, is viewed less intensely. These results support hypothesis $1(\mathrm{H1})$ : consumers with a positive attitude towards sustainable and regional foods look longer at individual display elements that address sustainability aspects.

The results demonstrate that the "sustainability important" group looked at AOls for a longer time (average of $0.39 \mathrm{sec}$ ). Not all test persons looked at the defined AOls. As a result, a tendency towards a stronger perception of individual AOls of the "sustainability important" group can be demonstrated. A total of 22 test persons looked at the picture "three bottles". Exactly 10 test persons of the group "sustainability important" fixed the $\mathrm{AOI}$ with an average of $1.36 \mathrm{sec}$. This indicates a stronger perception. Heading 2 was fixed by the group "sustainability unimportant" at $0.25 \mathrm{sec}$. On average, this is for a longer period by all AOls, whereby the sample of 3 test persons is notably small (table 1).

Figure 2

Display: areas of interests (AOIs) (left) and heat map (right)

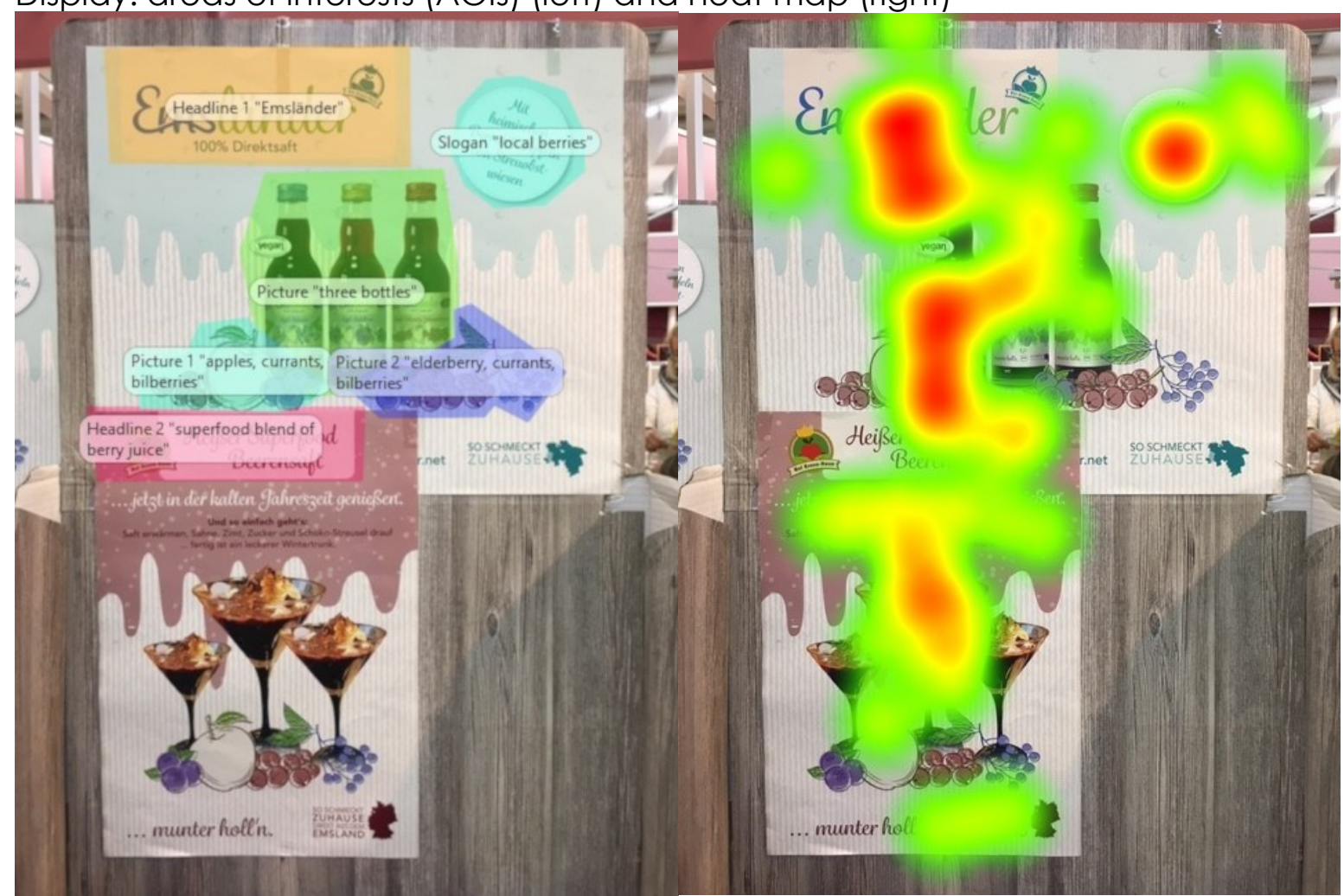

Note: left: representation of the 6 AOl's, right: absolute duration is calculated by the duration of fixations, whereas the warmest colour represents the highest value.

Source: Author's illustration 
Table 1

Total fixation duration (average): poster of display (frontal)

\begin{tabular}{lcccc}
\hline Total fixation duration (in sec./incl. zeros) & \multicolumn{4}{c}{ Display „Poster frontal“ } \\
\cline { 2 - 5 } AOI & \multicolumn{2}{c}{$\begin{array}{c}\text { Sustainability } \\
\text { important }\end{array}$} & $\begin{array}{c}\text { Sustainability } \\
\text { unimportant }\end{array}$ \\
\cline { 2 - 5 } & Mean & SD & Mean & SD \\
\hline Picture "three bottles" & $1.36^{*}$ & 2.19 & $0.44^{* *}$ & 0.50 \\
Slogan "local berries" & $0.33^{*}$ & 0.75 & $0.09^{* *}$ & 0.35 \\
\hline Headline 1 "Emsländer" & $0.28^{*}$ & 0.54 & $0.18^{* *}$ & 0.39 \\
\hline Headline 2 "Superfood blend of berry juice" & $0.18^{*}$ & 0.36 & $0.25^{* *}$ & 0.80 \\
\hline Picture 1 "apples, currants, bilberries" & $0.18^{*}$ & 0.43 & $0.06^{* *}$ & 0.15 \\
\hline Picture 2 "elderberry, currants, bilberries" & $0.04^{*}$ & 0.10 & $0.04^{* *}$ & 0.15 \\
\hline All & $\mathbf{0 . 3 9 ^ { * }}$ & $\mathbf{0 . 5 5}$ & $\mathbf{0 . 1 8 ^ { * * }}$ & $\mathbf{0 . 3 3}$ \\
\hline
\end{tabular}

Note: Total fixation duration (average) in seconds to $\mathrm{AOI}$ (include zeros)

*picture $n=10$, slogan $n=4$, headline $1 n=6$, headline $2 n=5$, picture $1 n=4$, picture $2 n=2$, all $n=12$ ** picture $n=12$, slogan $n=2$, headline $1 n=6$, headline $2 n=3$, picture $1 n=4$, picture $2 n=2$, all $\mathrm{n}=13$,

Source: Author's calculation

Overall, the gaze plot on the left in figure 3 visualizes the rather concentrated views of the individual AOl's. Hence, this supports the statement of the stronger perception of the group "sustainability important". This group looked at the display with an average of $3.47 \mathrm{sec}$. In contrast, the gaze plot on the right displays the rather diffuse and aimless glances of consumers who consider sustainability as unimportant. The average of the total fixation duration of the display with $1.72 \mathrm{sec}$. supports the result of a weaker perception of this group. The numbering of the circles indicates the order in which the customers view the individual AOl's. The size of the circles visualizes the duration of the view, which appears larger especially on the AOl's in the left gaze plot (Figure 3).

The memories of the special features of the newly introduced organic juice are well (2.00) to moderately (3.41) among all test persons. A comparison of the two groups of respondents shows that the "sustainability important" group remembered individual display elements better (overall 2.27) than the "sustainability unimportant" group (2.93) (see table 2). On average, the "sustainable important" group was also able to remember more distinct images. The mean values of comparison also demonstrates a significant difference between the two groups "sustainability important" (2.00) and "sustainability unimportant" (3.12) with regard to the memory of images on the packaging of the organic juice. Due to the small sample size, none of the other mean value comparisons revealed significant differences between the two groups. 
Figure 3

Gaze Plot „sustainability important" (left) vs. Gaze Plot „sustainability unimportant”

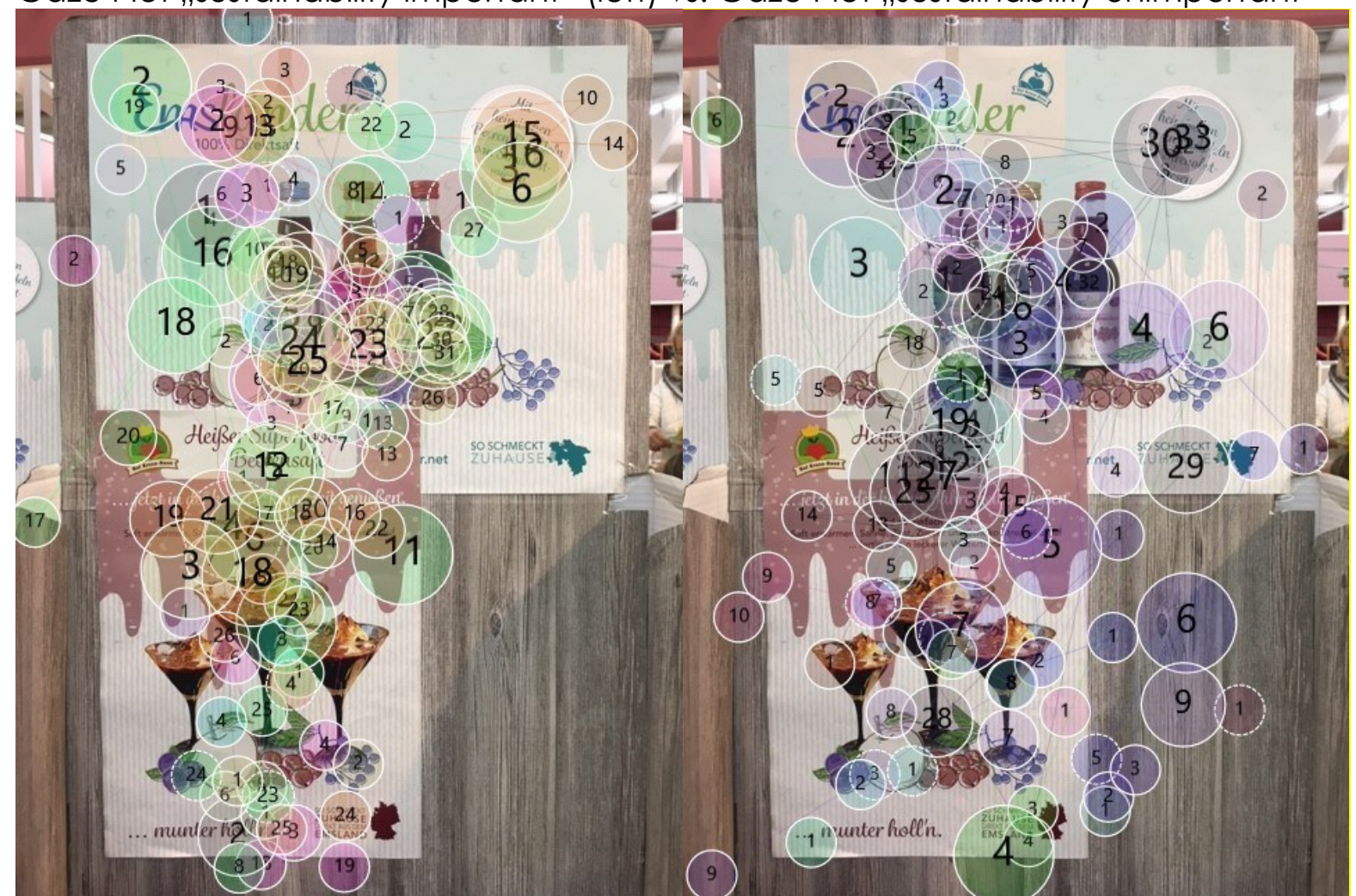

Note: left: illustration of the gaze plot "sustainability important" ( $n=17)$, right: illustration of the gaze plot "sustainability unimportant" ( $n=15)$

Source: Author's illustration

The results support hypothesis $2(\mathrm{H} 2)$ : subjects with a positive attitude towards sustainable and regional foods are more likely to remember individual display elements that visualize sustainability than subjects who are less open to this issue (table 2).

Table 2

Recollection of individual packaging or display elements

\begin{tabular}{lcccc}
\hline Questions & \multicolumn{2}{c}{$\begin{array}{c}\text { Sustainability } \\
\text { important }\end{array}$} & \multicolumn{2}{c}{$\begin{array}{c}\text { Sustainability } \\
\text { unimportant }\end{array}$} \\
\hline What can you remember? & Mean & SD & Mean & SD \\
I know what makes the juice special. & 2.27 & 1.16 & 3.00 & 1.36 \\
I remember the images on the juice bottle. & $2.00^{*}$ & 1.00 & $3.12^{*}$ & 1.16 \\
I remember the images on the display. & 2.73 & 1.48 & 3.41 & 1.06 \\
| know where the juice is produced. & 2.07 & 1.28 & 2.18 & 1.07 \\
\hline All & $\mathbf{2 . 2 7 ^ { * * }}$ & $\mathbf{0 . 8 3}$ & $\mathbf{2 . 9 3 ^ { * * }}$ & $\mathbf{0 . 7 7}$ \\
\hline
\end{tabular}

Note: Likert scale where $1=$ totally agree, $5=$ totally disagree

*t-Test: $p=0.007(p<0.05) \quad$ **t-Test: $p=0.028(p<0.05)$

Source: Author's calculation

The results of the survey in table 3 show whether the willingness to pay for a litre of direct fruit juice from the region and from organic production is positively influenced by consumers who regard sustainability as important. 
Table 3

Willingness to pay [in $€$ ] for one litre of direct juice from the region and from organic production

\begin{tabular}{|c|c|c|c|c|}
\hline \multirow{2}{*}{$\begin{array}{l}\text { Question } \\
\text { What is the maximum price you would pay? }\end{array}$} & \multicolumn{2}{|c|}{$\begin{array}{l}\text { Sustainability } \\
\text { important }\end{array}$} & \multicolumn{2}{|c|}{$\begin{array}{l}\text { Sustainability } \\
\text { unimportant }\end{array}$} \\
\hline & Mean & SD & Mean & $S D$ \\
\hline $\begin{array}{l}\text { For } 1 \text { litre direct fruit juice from a conventional } \\
\text { manufacturer, you pay about } € 1.80 \text { in the } \\
\text { supermarket. How much would you pay at } \\
\text { most for } 1 \text { litre of juice from the region and } \\
\text { organic production? }\end{array}$ & $2.78^{*}$ & 0.99 & $2.34^{*}$ & 0.92 \\
\hline
\end{tabular}

Note: values in $€$

* t-Test: $p=0.209(p<0.05)$

Source: author's calculation

The group "Sustainability is important" was prepared to pay an average of $€ 2.78$ for a litre of direct fruit juice. Consumers who were less open to sustainability said they would pay an average of $€ 2.34$ for a litre sustainable direct juice. Due to the high standard deviation for the small group sizes, the mean difference between the two customer groups is not statistically significant. Nevertheless, the absolute difference of as much as $\not \subset 44$ in the expressed willingness to pay indicates that customers who pay particular attention to the issue of sustainability tend to be more willing to pay for sustainable products than customers who are less open to this issue. Overall, it can thus be stated that there are at best weak indications that support hypothesis 3 .

\section{Discussion and conclusion}

The evaluation of the combined eye-tracking/survey study proved the fundamental suitability of this methodology for the analysis of display design for sustainable foods in a supermarket (field study). The study has demonstrated that, in addition to bottomup factors such as images, headlines and slogans on the display, top-down factors such as attitudes towards sustainable foods also influence consumer perception (Chandon et al., 2009; Wedel \& Pieters, 2008). At the point of sale, the results indicate that consumers with a positive attitude towards sustainable foods deal more intensively with the product information. The subsequent survey to remember individual elements on the juice bottle and the display confirms this. Due to the short observation period and orientation phase of consumers during shopping activities, the pictures and headlines on the display should be designed and placed in such a way that they achieve a high thematic significance. The results also indicate that a positive attitude towards sustainable foods tends to have a positive effect on consumers' willingness to pay (Behe et al., 2013). A study that examined the perception of fair trade labels also confirm this (Van Loo et al., 2015). In addition, the gaze recordings confirm that images and headlines in the upper part of the display, at eye level with the consumer, were increasingly perceived. Information, images and slogans on the lower poster were only perceived by a small number of consumers. For this reason, it is advisable to design the display with as little as possible text and images in order to achieve the highest possible initial attention at the point of sale (Clement et al., 2013). For the trader the study therefore provides new approaches for the design of the display. In particular, the display must not be overloaded with various topics that are ultimately not perceived. However, traders should focus on a few concise display elements that represent and communicate "sustainability". 
Further studies must analyse additional bottom-up factors such as shape and colour of individual elements and pictures of a display or product packaging in order to detect why an element attracts attention and why it is better perceived and remembered. This should be analyzed to understand why consumers ignore some elements and advertising slogans. The experience with regional food can also be included and, in conjunction with the demographic characteristics, provide clues as to how consumers visually evaluate a display before making a purchase decision (Huddleston et al., 2015). For example, an in depth analysis may be useful to detect whether a sustainability aspect is visualised with a single element. In addition, other metrics, such as fixation counts, can be used to analyse perception (van Loo et al., 2015).

One limitation of this eye-tracking study is the low number of samples. In particular, the eye-tracking metrics could not achieve a significant result due to fewer glances at individual AOls. This may change with a representative sample size (Lamberz et al., 2019). Another limitation of the study refers to the number of sample supermarkets. The study was conducted in only one single supermarket. The inclusion of further supermarkets has the potential to indicate the effect of different designs of supermarkets and increase the number of respondents. This extended approach may help to provide more insights into the perception of the packaging and display of the organic juice by different target groups at the point of sale.

Due to the weak tendency of consumers with a high sustainability, awareness to be more willing to pay, future studies should have a larger sample size and record the influence of socio-demographic variables. The incorporation of different pay grades, social status and higher education has the potential to provide more detailed insights into the willingness of target groups to pay (Grunert et al., 2014).

\section{References}

1. Aiking, H., de Boer, J. (2004), "Food sustainability: Diverging interpretations", British Food Journal, Vol. 106 No. 5, pp. 359-365.

2. Behe, B. K., Zhao, J., Sage, L., Huddleston, P. T., Minahan, S. (2013), "Display signs and involvement: The visual path to purchase intention", The International Review of Retail, Distribution and Consumer Research, Vol. 23 No. 5, pp. 51 1-522.

3. Chandon, P., Hutchinson, J. W., Bradlow, E. T., Young, S. H. (2009), "Does in-store marketing work? Effects of the number and position of shelf facings on brand attention and evaluation at the point of purchase", Journal of Marketing, Vol. 73 No. 6, pp. 1-17.

4. Choloewa-Wójcik, A, Kawecka, A. (2015), "The influence of effectiveness of packaging elements on the consumers' preferences with the use of marketing eye-tracking technique", Modern Management Review, Vol. 22 No. 1, pp. 49-61.

5. Clement, J., Kristensen, T., Grønhaug, K. (2013), "Understanding consumers' in-store visual perception: The influence of package design features on visual attention", Journal of Retailing and Consumer Services, Vol. 20 No. 2, pp. 234-239.

6. Diederichs, L., Göbl, M. (2018), "Displays in food retailing: An evaluation from a sales perspective", Journal of Applied Leadership and Management, Vol. 6, pp. 47-65.

7. Duchowski, A. T. (2007), Eye Tracking Methodology - Theory and Practice, Springer, London.

8. Fairtrade Deutschland. (2017), "Jahres- und Wirkungsbericht 2017" (Annual and impact report 2017), available at: https://www.fairtrade-

deutschland.de/service/mediathek?tx_igxmediathek_mediathek\%5Baction\%5D=list\& x_igxmediathek_mediathek\%5Bcontroller\%5D=Medium\&cHash=47f61 ebb53318c6f55d 331 d3efObb638 (13 October 2020)

9. Gröppel-Klein, A. (2007), "Konsumentenverhaltensforschung am Point-of-Sale", Magazin Forschung, Vol. 12 No. 2, pp. 14-19. 
10. Grunert, K. G. (2011), "Sustainability in the food sector: A consumer behaviour perspective", International Journal on Food System Dynamics, Vol. 2 No. 3, pp. 207-218.

11. Grunert, K. G., Hieke, S., Wills, J. (2014), "Sustainability labels on food products: Consumer motivation, understanding and use", Food Policy, Vol. 44, pp. 177-189.

12. Häusel, H.-G. (2016), "Brainview - Warum Kunden kaufen" (Brainview - Why customers buy), Haufe-Lexware, Freiburg.

13. Huddleston, P. T., Behe, B. K., Driesener, C., Minahan, S. (2018), "Inside-outside: Using eye-tracking to investigate search-choice processes in the retail environment", Journal of Retailing and Consumer Services, Vol. 43, pp. 85-93.

14. Huddleston, P., Behe, B. K., Minahan, S., Fernandez, R. T. (2015), "Seeking attention: An eye tracking study of in-store merchandise displays", International Journal of Retail \& Distribution Management, Vol. 43 No. 6, pp. 561-574.

15. Janssen, M., Hamm, U. (2012), "Product labelling in the market for organic food: Consumer preferences and willingness-to-pay for different organic certification logos", Food Quality and Preference, Vol. 25 No. 1, pp. 9-22.

16. Lamberz, J., Litfin, T., Teckert, Ö., Meeh-Bunse, G. (2019), "How does the attitude to sustainable food influence the perception of customers at the point of sale? - An Eyetracking study", Proceedings of the ENTRENOVA - ENTerprise REsearch InNOVAtion Conference, Vol. 5 No. 1, pp. 402-409.

Retrieved from https://proceedings.entrenova.org/entrenova/article/view/290 (20 April 2020)

17. Lee, J., Ahn, J. H. (2012), "Attention to banner ads and their effectiveness: An eyetracking approach", International Journal of Electronic Commerce, Vol. 17 No. 1, pp. 119-137.

18. Nordfält, J. (2011), "Improving the attention-capturing ability of special displays with the combination effect and the design effect", Journal of Retailing and Consumer Services, Vol. 18, No. 3, pp. 169-173.

19. Pieters, R., Warlop, L. (1999), "Visual attention during brand choice: The impact of time pressure and task motivation", International Journal of Research in Marketing, Vol. 16 No. 1, pp. 1-16.

20. Pieters, R., Warlop, L., Wedel, M. (2002), "Breaking through the clutter: Benefits of advertisement originality and familiarity for brand attention and memory", Management Science, Vol. 48 No. 6, pp. 765-781.

21. Russo, J. E., (1978), "Eye fixations can save the world: A critical evaluation and a comparison between eye fixations and other information processing methodologies", in Hunt, H. K. (Ed.), Advances in Consumer Research, Association for Consumer Research, Ann Arbor, pp. 561-570.

22. Samant, S. S., Seo, H. S. (2016), "Effects of label understanding level on consumers' visual attention toward sustainability and process-related label claims found on chicken meat products", Food Quality and Preference, Vol. 50, pp. 48-56.

23. Van Loo, E. J., Caputo, V., Nayga Jr, R. M., Seo, H. S., Zhang, B., Verbeke, W. (2015), "Sustainability labels on coffee: Consumer preferences, willingness-to-pay and visual attention to attributes", Ecological Economics, Vol. 118, pp. 215-225.

24. von Meyer-Höfer, M. (2016), "Erwartungen schweizerischer und deutscher Verbraucher an nachhaltige Lebensmittel" (Swiss and German consumers" expectations of sustainable food), Journal of Socio-Economics in Agriculture, Vol. 9, pp. 1-13.

25. Wästlund, E., Shams, P., Otterbring, T. (2018), "Unsold is unseen ... or is it? Examining the role of peripheral vision in the consumer choice process using eye-tracking methodology", Appetite, Vol. 120, pp. 49-56.

26. Wedel, M., Pieters, R. (2008), "A review of eye-tracking research", in Malhotra, N. K. (Ed.), Review of Marketing Research, Emerald Group Publishing Limited, New York, pp. 123147. 


\section{About the authors}

Julia Lamberz is currently a Research Assistant at Osnabrück University of Applied Sciences' Lingen Campus with a focus on marketing research. She received her Master's degree in Science Marketing from the Technische Universität Berlin. She can be contacted at j.lamberz@hs-osnabrueck.de.

Thorsten Litfin is a Professor of Marketing, Service and Innovation Management at Osnabrück University of Applied Sciences 'Lingen Campus. He received his PhD from the Institute of Innovation Management at Christian-Albrechts-University of Kiel. His research interests include product and pricing strategies for innovative products and services. He can be contacted at t.litfin@hs-osnabrueck.de.

Özlem Teckert is currently a Research Assistant at Osnabrück University of Applied Sciences' Lingen Campus with a focus on marketing research. She received her Master's degree in Economics and Laws from the University of Oldenburg and is currently a PhD candidate in the Department of Business Administration, Economics, and Law. She can be contacted at o.teckert@hs-osnabrueck.de.

Gunther Meeh-Bunse is a Professor of Finance and Accounting at the University of Applied Sciences at Osnabrück' Lingen Campus. He studied business administration at the University of Saarland and received his PhD from the University of German Armed Forces in Munich. His research interests include managerial accounting and corporate social responsibility. Author can be contacted at g.meeh-bunse@hsosnabrueck.de. 